\title{
Model Development for Life Cycle Assessment of Rice Yellow Stem Borer under Rising Temperature Scenarios
}

\author{
Jatish C Biswas ${ }^{1}$, M Maniruzzaman' ${ }^{2}$, MB Hossain ${ }^{2}$, Hazrat Ali ${ }^{1}$, Wais Kabir ${ }^{1}$ and N Kalra ${ }^{3 *}$ \\ ${ }^{1}$ Krishi Gobeshona Foundation (KGF), Bangladesh \\ ${ }^{2}$ IWM Division, Bangladesh Rice Research Institute, Bangladesh \\ ${ }^{3}$ Division of Agricultural Physics, Indian Agricultural Research Institute, India
}

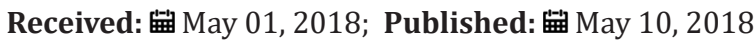

*Corresponding author: N Kalra, Division of Agricultural Physics, Indian Agricultural Research Institute, India

\begin{abstract}
A simple model was developed using Fortran Simulation Translator to study the influence of increased temperature on duration of various life cycle phases of yellow stem borer (YSB) in Bangladesh environment. Model was primarily based on Growing Degree Day concept, by also including cardinal temperatures sensitive for specific growing stages of YSB. After successful calibration and validation of the model, it was taken for climate change (only temperature rise considered in the present study) impact analysis on the growing cycle of YSB. Temperature increase values of 1, 2, 3 and 4 oC were considered and compared with the Control (no temperature rise), by using historic weather of representative locations in eight Divisions of Bangladesh. Differential spatial response in the life cycle of YSB under various temperature rise treatments was noticed, and in general the growing cycle hastened with the rising temperature. The life cycle of YSB is likely to be reduced by about 2 days for every degree celcius rise in temperature, while averaged over locations. This means that there will be 2.0-2.5 additional generations of YSB in pre-monsoon season about 2.9-3.2 in wet season of Bangladesh. There is a need to include the phenology module developed in subsequent design of population dynamics model for YSB.
\end{abstract}

Keywords: Model; Growing degree days; Yellow stem borer; Life cycle assessment; Temperature rise

\section{Introduction}

Yellow stem borer (YSB) is the most destructive and widely distributed insect-pest of rice. It causes dead heart or white head, depending on infestation time and significantly reduces rice yields by $5-10 \%$ and even up to $60 \%$ under localized outbreak conditions [1]. It can grow in places having temperature $>12 \mathrm{oC}$ and annual rainfall around $1000 \mathrm{~mm}$. Generally, temperature and high relative humidity (RH) in the evening favors stem borer growth and development [2]. The female moth oviposits from 1900 to $2200 \mathrm{hr}$ in summer, 1800 to $2000 \mathrm{hr}$ in spring and autumn, and deposits one egg mass in a night and up to five nights after emergence. Optimum temperature is $29 \mathrm{oC}$ having $90 \% \mathrm{RH}$ for maximum number of eggs deposition. Optimum temperature for egg hatching is $24-29 \mathrm{oC}$ with $90-100 \% \mathrm{RH}$. Larvae die at $35 \mathrm{oC}$ and hatching is severely reduced when RH goes to below 70\% [1]. Larvae can't molt at $12 \mathrm{oC}$ or below and they die. The last instar larvae can survive unfavorable growth condition as diapauses, which is broken by rainfall or flooding. In multiple rice cropping, no diapauses takes place. The pupal period can last for 9-12 days and the threshold temperature for its development is $15-16 \mathrm{oC}$.

The number of generations in a year depends on temperature, rainfall and the availability of host [1]. The occurrence of the pest is generally the highest in wet season [3]. Since there are many stem borer species, the average life cycle of rice stem borers varies from 42-83 days [4], depending on growing conditions. This implies that heterogeneous population can be found in the same rice field. Manikandan [5] also reported that development time by different phases of YSB decreases with higher temperature and thus increased population likely in future at early growth stages 
of rice crop. However, no such data is available in Bangladesh. Keeping the acute problem of YSB in Bangladesh, the present study was undertaken to develop a simple phenology-based) model to assess the life cycle of YSB in two major growing seasons of rice and subsequent taking it to evaluate the effect of rising temperature on growth cycle of rice yellow stem borer in representative locations of eight Divisions of Bangladesh.

\section{Materials and Methods}

\section{Model description}

Model for assessing the phenology of yellow stem borer was written in Fortran Simulation Translator and the compiler used is FSTWin 4.12 [6]. This model will subsequently be used to develop population dynamics model for YSB in rice-based cropping systems prevalent in Bangladesh. Growing degree days (GDD) concept was used for this purpose, with base temperature assumed as 15 degree Celsius, below which growth and development activity in the life cycle of YSB does not take place. Each day, average temperature (mean of maximum and minimum temperatures) minus the base temperature is integrated over the growing cycle, and subsequently the development stage is achieved when critical value for attainment of a particular stage is crossed.

In the INITIAL phase, the GDD is taken as zero, which is read one time during running of the model

INCON GDDI, initial value of GDD = 0.

In the DYNAMIC phase, the program is executed daily till the FINISH Condition is achieved.

DAS, days after start of simulation = INTGRL (ZERO, RDAS)

PARAM RDAS, day increment rate $=1$.

The development stage can be expressed in development stage $(0-1)$, but in the present study not used for development stage identification, which we will use in further design of population dynamics model in coming times.

DVS, development stage $=I N T G R L(Z E R O, D V R)$

DVR, rate of development stage increase, Arbitrary Function Generator- $a$ well defined FST function=AFGEN (DVRT, DAVTMP)

Since the age of male is relatively lower than the age of the female, so the computation is done separately as indicated below:

\section{*FOR FEMALE}

FUNCTION DVRT = -10.,0., 0.,0.,15.,0.,35.,0.03325,40.,0.0415

*FOR MALE

FUNCTION DVRT = -10.,0., 0.,0.,15.,0.,35.,0.0342,40.,0.0426

Base temperature below which the activities do not take place, degree celcius, is given as under:

\section{PARAM TBASE $=15$.}

Reading of weather data, on daily time step, is read through external file, as per well defined format for FST compiler, as given below:

WEATHER WTRDIR='C: $\mid$ WEATHER|';CNTR='GAZI';ISTN=1;I$Y E A R=200$

Where, various climatic elements are used as below:

$\mathrm{RDD}$ is solar radiation in $\mathrm{J} / \mathrm{m} 2 /$ day

$D T R=R D D$

TMMX is daily maximum temperature; COTEMP is the climate change, temperature rise switch for evaluating the impact of temperature rise on the phenological development of the life cycle of YSB. TMMN is daily minimum temperature.

$D T M A X=T M M X+C O T E M P$

$D T M I N=T M M N+C O T E M P$

DAVTMP, average temperature (derived parameter) $=0.5^{*}$ $(D T M A X+D T M I N)$

DDTMP, day time average temperature, derived parameter $=$ DTMAX $-0.25^{*}$ (DTMAX-DTMIN)

COTEMP is temperature rise/fall switch

PARAM COTEMP $=0$.

DTEFF, effective temperature after deducting the base temperature $=\operatorname{AMAX1}(0 .$, DAVTMP-TBASE $)$

SVP, is saturated vapor pressure in mbar, calculated from temperature (derived value)

$S V P=6.11^{*} E X P\left(17.4^{*} D A V T M P /(D A V T M P+239.1)\right) / 10$.

VP is Actual vapor Pressure, mbar, an input for running of the model

$A V P=V P$

$\mathrm{RH}$ is relative humidity, expressed in \%, derived from the vapor pressure as below:

$R H=A V P / S V P^{*} 100$.

In the present study, only temperature and relative humidity effects are undertaken for computation of the phonological stages of the life cycle of YSB, although we have described the other climatic elements as part of the FST compiler, but the other parameters will also be used in deriving the population dynamics model, which we will take up in later course of time.

Since the development stages of YSB are influenced by relative humidity also, so we have to introduce the correction factor for including the effect of humidity, as below: 
DAVTMPCF, RH induced temperature correction $=D A V T M P^{*} C F R H$ $T M P E F F=D A V T M P C F-T B A S E$

CFRH is the Correction Factor for relative humidity for judging temperature is computed as below: i.e. during hatching (CFRHH) and larva formation (CFRHL) stages, computed as below:

CFRH, correction factor for RH=INSW (GDD-EGHATCH, CFRHH, DUM11)

DUM11=INSW (GDD-979.9,CFRHL,1.)

Where INSW is FST Function, if GDD<979.9, then CFRHHD is taken and otherwise DUM11

\section{CFRHH=AFGEN (CFRHHT, RH)}

$C F R H L=A F G E N(C F R H L T, R H)$

FUNCTION CFRHHT=50.,0.9,60.,0.9,75.,1.,90.,1.1

FUNCTION CFRHLT=50.,0.95,60.,0.95,75.,1.,90.,1.05

$W D S$, wind speed in $m / s e c=W N$

RRAIN, daily rainfall in $\mathrm{mm}=\mathrm{RAIN}$

TRAIN, total rainfall in $\mathrm{mm}=$ INTGRL (ZERO, RRAIN)

GDD is growing degree days, expressed in degree Celsius-days, is calculated as below:

\section{$G D D=I N T G R L(G D D I, T M P E F F)$}

On the basis of literature search from the published literature, the growing degree days for various stages were computed and used in development of the model, and is described as below:

EGHATCH is the thermal degree days requirement for egg hatch, is as below:

\section{PARAM EGHATCH=119.7}

INSTAR1 is thermal degree days for end of first instar 1 stage

\section{PARAM INSTAR1=224.9}

INSTAR2 is thermal degree days for end of second instar stage

PARAM INSTAR2 $=317.0$

INSTAR3 is thermal degree days for end of third instar stage

PARAM INSTAR3=438.7

INSTAR4 is thermal degree days for end of fourth instar (larva) stage

PARAM INSTAR4 $=550.3$

PUPA, is thermal degree days for end of pupa stage

PARAM PUPA $=662.452$
ADULT LONGIVITY is thermal degree days for end of adult longevity, which is different for male/female, For Male=741.484 and Female=773.538, depending upon the defined parameter SEX

ADULT $=$ INSW (SEX-1.05, FEMALE, MALE)

*SEX=1. For female and 2. For male

PARAM SEX $=2$

PARAM MALE, growing degree days for male $=741.484$

PARAM FEMALE, growing degree day for female $=773.538$

Critical temperature above which the egg hatching stops is defined as below:

\section{$D E A T H=R E A A N D(E G H A T C H-G D D, D T M A X-40$.}

HATMI, minimum temperature below which the Hatching stops, is defined as below

PARAM HATMIN=15.

\section{DEATH1=REAAND (EGHATCH-GDD, HATMIN-DTMIN)}

LATMIN, minimum temperature below which larval growing stages stop, and is given as under:

\section{PARAM LATMIN=12.}

DEATH2=INSW (GDD-EGHATCH,0.,REAAND(INSTAR4-GDD,LATMIN-DTMIN))

REAAND is FST Function, which will be 1 when both the variables within parenthesis are greater than zero; otherwise the value will be 0 .

Duration of various stages is computed as below:

EGHATCHD is egg hatch duration, in days and computed as below:

$E G H A T C H D=I N T G R L(Z E R O, D U M 1)$

DUM1=INSW (EGHATCH-GDD,0.,1.)

INSTAR1D is INSTAR1 Termination Day

INSTAR1D=INTGRL (ZERO, DUM2)

DUM2=INSW (INSTAR1-GDD, 0.,1.)

INSTAR2D is INSTAR2 Termination Day

INSTAR2D=INTGRL (ZERO, DUM3)

DUM3 =INSW (INSTAR2-GDD, 0.,1.)

INSTAR3D is INSTAR3 Termination Day

INSTAR3D=INTGRL (ZERO, DUM4)

DUM4=INSW (INSTAR3-GDD, 0.,1.) 
INSTAR4D is INSTAR4 Termination Day

INSTAR4D=INTGRL (ZERO, DUM5)

DUM5=INSW (INSTAR4-GDD, 0.,1.)

PUPAD is PUPA Stage Termination Day

$P U P A D=I N T G R L$ (ZERO, DUM6)

DUM6=INSW (PUPA-GDD,0.,1.)

ADULTD is Adult Life End Day

ADULTD $=I N T G R L(Z E R O, D U M 7)$

DUM7=INSW (ADULT-GDD, 0.,1.)

Stop of Run Condition is as under:

FINISH DEATH > 0.95

FINISH GDD> 775.

Integration conditions for running of the program are as under:

TIMER STTIME $=360 .$, FINTIM $=600 .$, DELT $=1 ., P R D E L=1$.

\section{TRANSLATION GENERAL DRIVER='EUDRIV'}

PRINT DAY, DOY, DVS, RH, AVP, SVP, WDS, TRAIN, GDD, DAVTMP, DAVTMPCF, ADULTD, PUPAD

In the TERMINAL stage, the final values at the stop of model run can be written in an external file:

CALL SUBWRI (TIME, COTEMP, EGHATCHD, INSTAR1D, INSTAR2D, INSTAR3D, INSTAR4D, PUPAD, ADULTD)
END

Reruns options for evaluating the impact of temperature rise on the development stages of the YSB can be run through this given below procedure:

PARAM COTEMP=1.

END

PARAM COTEMP=2.

END

STOP

\section{Experimental}

Growing degree days for attainment of various growing stages in the life cycle of YSB were collated from the published literature in this region. The model was calibrated with 2003 weather data of Bhola district of Bangladesh against the findings of Manikandan [5] at 30 oC. After model calibration, it was subsequently taken to climate change window, temperature rise only considered in the present study. Eight divisions (Dhaka, Mymensingh, Rajshahi, Rangpur, Sylhet, Khulna, Chittagong and Barisal) of Bangladesh were taken and one representative location was chosen from each division and historic weather data of 35 years were taken for running of the model and the duration of each development stage was computed and compared amongst temperature rising conditions. In the present study, daily temperature rise from 1-4 oC were considered for two growing seasons, Aus rice season i.e. premonsoon (April to June) and Aman Rice season i.e. Monsoon (late June to November) of Bangladesh.

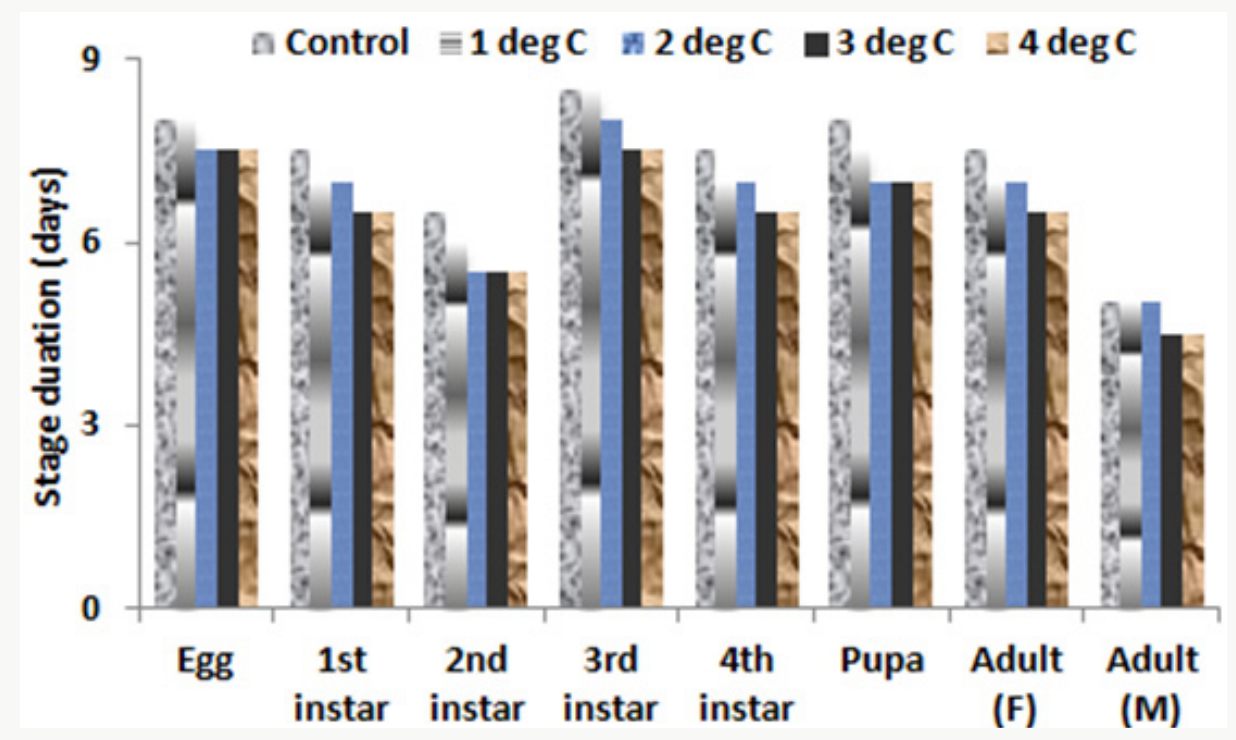

Figure 1: Days required for completion of growth stages of rice yellow stem borer with increased temperature by 1, 2, 3 and 4 degree celcius in the growing environment of Bhola, Bangladesh.

\section{Results and Discussion}

During the test period, minimum temperature averaged $26 \pm 0.115$ and maximum temperature around $31 \pm 0.32$, with the average temperature around $30 \mathrm{oC}$, which was used for calibration and validation of the model, and the model performed satisfactorily well, through nice agreement between observed and simulated 
results (Table 1). Depending on growth stages, the percent deviations were within the limit of model errors. The application of model for specific years of Bhola district showed that the growth stages of rice yellow stem borer (YSB) were decreasing (Figure 1) by about 1.76 days per degree rise in temperature $(Y=1.7 \mathrm{X}+54.6$; $\mathrm{R} 2=0.932$ ). This indicated that YSB is likely to infest more rice plants in future under increased temperature conditions. Ramya [7] also reported that YSB would likely to develop faster, oviposit early and thus enhanced population build up than expected. There are reports that temperature increase by $20 \mathrm{C}$ may cause 1-5 times additional life cycles of insects in a season [8].

Table 1: Validation of various growth phases (days) of rice yellow stem borer.

\begin{tabular}{|c|c|c|c|c|c|c|c|c|}
\hline Stage & Egg & $\mathbf{1}^{\text {st }}$ instar & $\mathbf{2}^{\text {nd }}$ instar & $\mathbf{3}^{\text {rd }}$ instar & $\mathbf{4}^{\text {th }}$ instar & Pupa & Adult (F) & Adult (M) \\
\hline Observed & 7.8 & 7 & 5.5 & 7.5 & 7 & 7.3 & 7 & 5.3 \\
\hline Simulated & 8 & 7 & 6.1 & 8 & 7.5 & 8 & 7.5 & 5 \\
\hline \% deviation & 3.2 & 0 & 10.9 & 6.7 & 7.1 & 10.3 & 7.1 & -4.8 \\
\hline
\end{tabular}

Results, from represented locations in the eight Divisions of in the Aus season and 1.70 days in T. Aman season (Figure 2). Bangladesh, showed that growth stage of YSB varied depending on season (Table 2). In Aus pre-monsoon season, life cycle of YSB would likely to be completed within 47-53 days, depending on locations and temperature rise from 1-4 degree celcius. Similarly in Aman wet season, it would about 45-50 days for temperature rice from 1-4 degree celcius. However, under the Control (no temperature rise) condition, it requires around 52 days for T. Aman and 55 days for Aus. Our findings indicate that growth cycle of YSB is likely to decrease by 2.04 days per degree rise in temperature

Similar results were reported by Manikandan [5]. Generally, insect population build up depends on favorable weather conditions and availability of host. So, there will be ups and downs in the peak build ups in a cropping season [9]. Although model data needs to be cautiously adopted, it clearly showed that with climate change impact the infestation of YSB would be increased, which might be cause of yield reduction, if not proper management is taken at the right time [10].

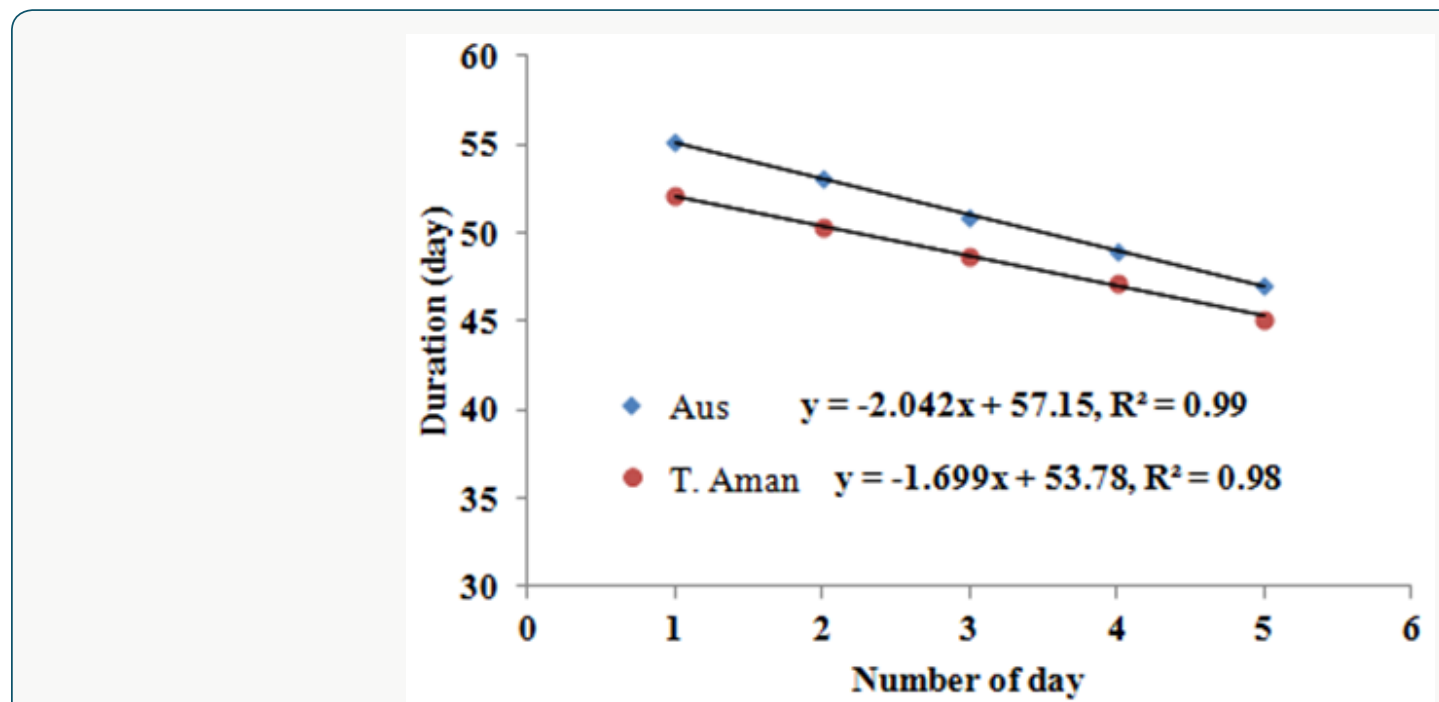

Figure 2: Total life cycle duration of yellow stem borer as influenced by temperature rise during Aus and T. Aman, season (averaged over eight Divisions of Bangladesh).

Table 2: Developmental phases (in days) of rice yellow stem borer as influenced by temperature rise in different growing seasons.

\begin{tabular}{|c|c|c|c|c|c|}
\hline \multicolumn{6}{|c|}{ Temperature rise $\left({ }^{\circ} \mathrm{C}\right)$} \\
\hline & 0 & 1 & 2 & 3 & 4 \\
\hline \multicolumn{6}{|c|}{ T. Aus } \\
\hline Egg development & $9.25 \pm 0.71$ & $9.25 \pm 0.71$ & $9.00 \pm 0.76$ & $9.00 \pm 0.76$ & $8.88 \pm 0.64$ \\
\hline First instar & $7.63 \pm 0.74$ & $7.13 \pm 0.64$ & $7.13 \pm 0.35$ & $6.75 \pm 0.46$ & $6.38 \pm 0.52$ \\
\hline Second instar & $6.38 \pm 0.52$ & $6.25 \pm 0.46$ & $6.13 \pm 0.64$ & $5.75 \pm 0.46$ & $5.63 \pm 0.52$ \\
\hline Third instar & $8.50 \pm 0.53$ & $8.13 \pm 0.64$ & $7.63 \pm 0.52$ & $7.50 \pm 0.53$ & $7.25 \pm 0.46$ \\
\hline Fourth instar & $7.50 \pm 0.53$ & $7.38 \pm 0.52$ & $7.13 \pm 0.64$ & $6.75 \pm 0.46$ & $6.63 \pm 0.52$ \\
\hline Larva & $30.0 \pm 1.70$ & $28.9 \pm 1.60$ & $28.0 \pm 1.30$ & $26.8 \pm 1.20$ & $25.9 \pm 1.50$ \\
\hline
\end{tabular}




\begin{tabular}{|c|c|c|c|c|c|c|}
\hline Pupa & $8.00 \pm 0.53$ & $7.25 \pm 0.46$ & $7.13 \pm 0.35$ & $6.63 \pm 0.74$ & $6.25 \pm 0.46$ \\
\hline Female longevity & $7.88 \pm 0.35$ & $7.75 \pm 0.46$ & $6.75 \pm 0.46$ & $6.50 \pm 0.53$ & $6.00 \pm 0.53$ \\
\hline Male longevity & $5.88 \pm 0.35$ & $5.50 \pm 0.53$ & $4.75 \pm 0.46$ & \multicolumn{2}{|c|}{$4.75 \pm 0.46$} & $4.38 \pm 0.52$ \\
\hline \multicolumn{7}{|c|}{ T. Aman } \\
\hline Egg development & $8.19 \pm 0.26$ & $7.88 \pm 0.23$ & $7.81 \pm 0.26$ & $7.69 \pm 0.26$ & $7.19 \pm 0.26$ \\
\hline First instar & $7.25 \pm 0.46$ & $6.88 \pm 0.35$ & $6.75 \pm 0.46$ & $6.25 \pm 0.46$ & $6.00 \pm 0.23$ \\
\hline Second instar & $6.13 \pm 0.35$ & $5.88 \pm 0.35$ & $5.63 \pm 0.52$ & $5.50 \pm 0.53$ & $5.50 \pm 0.53$ \\
\hline Third instar & $8.13 \pm 0.64$ & $7.94 \pm 0.18$ & $7.63 \pm 0.52$ & $7.50 \pm 0.53$ & $7.25 \pm 0.46$ \\
\hline Fourth instar & $7.50 \pm 0.53$ & $7.25 \pm 0.46$ & $7.13 \pm 0.35$ & $6.75 \pm 0.46$ & $6.38 \pm 0.52$ \\
\hline Larva & $29.0 \pm 0.76$ & $28.0 \pm 0.76$ & $27.0 \pm 0.76$ & $26.0 \pm 0.76$ & $25.1 \pm 0.64$ \\
\hline Pupa & $7.63 \pm 0.52$ & $7.13 \pm 0.35$ & $7.06 \pm 0.18$ & $6.63 \pm 0.52$ & $6.38 \pm 0.52$ \\
\hline Female longevity & $7.25 \pm 0.46$ & $7.38 \pm 0.52$ & $6.75 \pm 0.46$ & $6.88 \pm 0.35$ & $6.50 \pm 0.53$ \\
\hline Male longevity & $5.13 \pm 0.35$ & $5.25 \pm 0.46$ & $4.75 \pm 0.46$ & $4.88 \pm 0.35$ & $4.63 \pm 0.52$ \\
\hline
\end{tabular}

\section{Conclusion}

Yellow stem borer of rice crop is a major concern in Bangladesh. Dead hearts and white heads caused by YSB significantly reduce growth and yield of rice crops, especially in Aus (Pre-monsoon) and T. Aman (Monsoon) seasons. There is a need to understand the phenology i.e. life cycle assessment and population dynamics of YSB in the growing environments of Bangladesh. In the present study, a simple model, as written in Fortran Simulation Translator (FST), was developed to assess the life cycle of YSB. The model was primarily based on growing degree day's concept, by also considering cardinal temperatures for specific phenological/ development growth stages of YSB. The model was successfully validated with the growing environment of Bhola district of Bangladesh. Subsequently, the model was taken to assess the impact of rise in temperature on life cycle of YSB in representative locations of eight Divisions of Bangladesh. The response was spatiotemporally and seasonally variable. The life cycle hastened with the rise in temperature by 1-4 degree celcius. We, in near future, plan to develop a population dynamics model for YSB and to subsequently link it with the rice growth model to evaluate the yield reductions associated with YSB infestations.

\section{Acknowledgement}

We greatly acknowledge the support of Krishi Gobeshona Foundation, Dhaka, Bangladesh in conducting this research through CRP-II project.

\section{References}

1. Pathak MD, ZR Khan (1994) Insect Pest of Rice: Stem borers. International Rice Research Institute, Manila, Philippines, pp. 5-17.
2. Madhuri G, PC Dash, KK Rout (2017) Effect of weather parameters on population dynamics of paddy pests. Intl J Curr Microbiol App Sci 6(10): 2049-2053.

3. Chattopadhyay N, RP Samui (2003) Weather based forewarning of stem borer (Scirpophaga incertulas) on rice. MAUSAM 54(3): 695-704.

4. Srivastava SK, M Salim, A Rehman, A Singh, DK Garg, et al. (2003) Stem borer of rice-wheat cropping system: Status, diagnosis, biology and management. Rice-wheat Consortium Bull. Series. Rice-wheat consortium for the Indo-Gangetic Plains, New Delhi.

5. Manikandan N, JS Kennedy, V Geethalakshmi (2013) Effect of elevated temperature on development time of rice yellow stem borer. Indian J Sci Tech 6(12): 5563-5566.

6. Rappoldt C, DW G van Kraalingen (1996) Introduction and Reference Manual. The Fortran Simulation Translator, FST version 2.0. Quantitative Approaches in System Analysis.

7. Ramya M, JS Kennedy, VG Lakshmi, A Lakshmana, N Manikandan, et al. (2012) Impact of elevated temperature on major pests of rice. CLIMARICE Technical Brief No. 10, p. 6.

8. Yamamura K, K kiritani (1998) A simple method to estimate the potential increase in the number of generations under global warming in temperate zones. Appl Ent Zool 33(2): 289-298.

9. Rana R, G Singh, AK Tanwar, R Kumar (2017) Effect of weather parameters on the infestation of yellow stem borer, Sirpophaga incertulas Walker in basmati rice. J Entom Zoology Studies 5(3): 24-27.

10. Bale J, Masters G (2002) Herbivory in global climate change research: direct effects of rising temperature on insect herbivores. Journal of Global Change Biology 8(1): 1-16. 
(C) (P) This work is licensed under Creative Commons Attribution 4.0 License

To Submit Your Article Click Here: Submit Article

DOI: 10.32474/CIACR.2018.02.000144

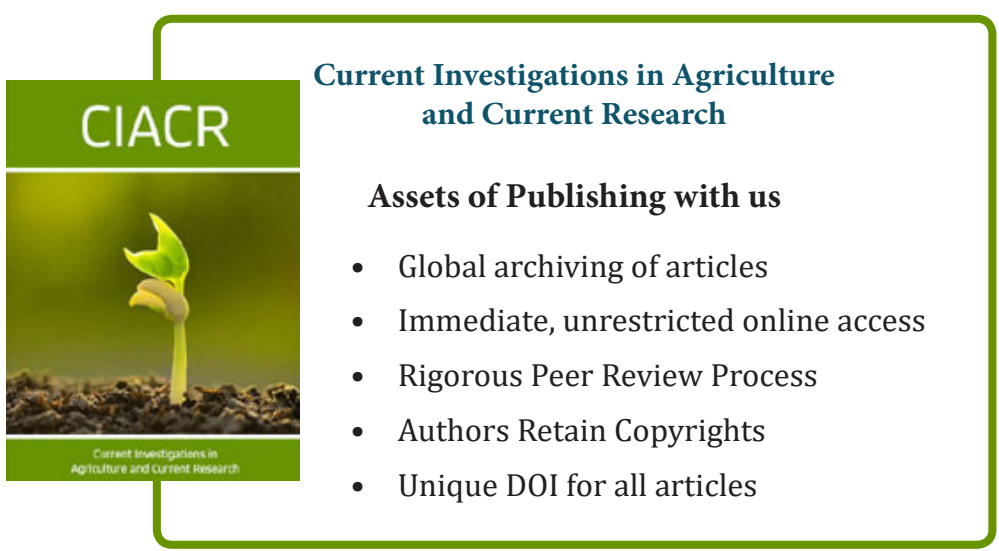

